\title{
EL MONESTIR DE SANTA MARIA DE JONQUERES (BARCELONA) DURANT LA LLOCTINËNCIA DE JOAN D'ANJOU, DUC DE LORENA (1467 A 1470)
}

\section{Francina Solsona Climent (†)}

Entre la documentació conservada a la Sèrie Intrusos' de l'Arxiu de la Corona d'Aragó i, concretament, als registres de la Reial Cancelleria, núm. 33, 34, 35 i 50, de la lloctinència de Joan d'Anjou, fill del duc Renat, rival de Joan II a l'època de les torbacions ${ }^{2}$, hi figuren algunes provisions referents a

1 Els reis que figuren en aquesta secció són: Enric IV de Castella, el conestable Pere de Portugal i René d'Anjou, tots tres de l'època de Joan II (al llom del registre i a primera fulla, moltes vegades pot llegir-se: «Turbationes Johan II $)$ ). El rei Joan II va tenir un gran interès a conservar la documentació dels seus rivals (Pragmàtica del 30 de novembre 1472, citada per MARTiNez FERRANDo, J.E. El Archivo de la Corona de Aragón, Ed. Aymà, Barcelona 1954, p. 46. També en parla al seu Discurs llegit a la Reial Acadèmia de Bones Lletres de Barcelona, el 6 juliol. 1941, Nueva visión y síntesis del gobierno intruso de Renato de Anjou. Seguint el seu exemple, tampoc els reis de la Casa d'Àustria i de Borbó no van destruir els registres i papers dels «intrusos» reis de França Lluis XIII i Lluís XIV i de l'arxiduc Carles d'Ảustria, també col-locats dins d'aquesta Secció.

${ }^{2}$ A la mort de Pere el Conestable, quan tothom ja pensava en la possibilitat d'una pau, la Generalitat de Catalunya va enviar una ambaixada al rei René d'Anjou, prescindint del testament del Conestable, nét del comte d'Urgell, que deixava com a successor el primogènit del rei de Portugal, besnét del comte d'Urgell (Martínez Ferrando, Nueva visión, 8). 
monges del monestir de Jonqueres ${ }^{3}$, que ens ha semblat interessant donar a conèixer i comentar breument, ja que poden completar alguns aspectes del convent en aquells temps de guerra fratricida.

Ja de bell punt cau per terra la teoria de Joan II sobre la conducta de les monges en temps del lloctinent del «bon roi René». L'any 1472 (darrer document de l'apèndix), Joan II es dirigia a les autoritats del regne d'Aragó, principat de Catalunya i regne de València, demanant la devolució a les monges de Jonqueres de totes les seves rendes i possessions situades en el territori respectiu. Diu el rei: «menti habemus quod superioribus annis, informate quod religiose et dilecte nostre priorisse, moniales et conventus Monasterii de Junqueriis... quamquam in eadem civitate tunc nobis fidelissime et affectatissime erant, suasque preces et oraciones ad Dominum pro nostri vita et incolumitate, nostrisque status prosperitate continue porrigebant ${ }^{4}$.

Bé, potser sí que algunes monges demanaven al Cel la victòria del rei sobre els seus orgullosos súbdits, però el cas és que aquestes que nosaltres presentem: Anneta de Rocacrespa, Marquesa de Santa Pau i la mateixa prioressa Agnès Romeu no van dubtar a dirigir-se a Joan d'Anjou per demanar els favors que tot seguit s'especifiquen.

La referència més anterior dels documents presentats (doc. I) parla del conflicte judicial existent entre la monja Anneta, del monestir de Jonqueres, orde de Sant Jaume, i la seva germana

${ }^{3}$ El monestí femení de Jonqueres es va fundar el 1214 a Sant Vicenç de Jonqueres, dins del terme de Sabadell, però no prosperà fins que trobà un assentament definitiu a la ciutat de Barcelona l'any 1293, prop de l'antiga muralla, a l'actual carrer de Jonqueres. Ací adoptà la regla de l'orde militar d'Uclès o de Sant Jaume de l'Espasa (Pladevall, Antoni dins la Gran Enciclopèdia Catalana).

${ }^{4}$ Citat per Maria-Mercè CostA, «Les dames nobles de Jonqueres», extret de Col-loqui d'Història del Monaquisme Català, vol. Il (Scriptorium Populeti 9), Abadia de Poblet, 1974, p. 255, nota 6, i també a «Les eleccions priorals al Monestir de Santa Maria de Jonqueres", separata dels Quaderns d'A rqueologia i itistòria de la ciutat. Seminari d'investigació «A. Duran i Sanpere», p. 6, nota 8. Publicat integre a l'apèndix, document núm. 5. 
donzella Violant o Isabel, ja que està escrit de les dues maneres, filles del cavaller Pere Antoni de Rocacrespas ${ }^{5}$, partidari de Joan II. El contrincant era el guerrer o home d'armes anomenat «lo petit francès», que ja Martínez Ferrando cita al seu catàleg sobre Pere el Conestable ${ }^{6}$.

Joan d'Anjou encomana al doctor en lleis i regent de la Cancelleria, Joan May ${ }^{\top}$, la solució del cas, i fa constar que tenia coneixement de la pobresa de les dues germanes i confiava que aplicaria la precisa justicia.

La monja Agneta de Rocacrespa no posseïa gaires diners, potser perquè havia fet el vot de pobresa, però, en canvi, segons es veu, anys a venir tenia «la inspiració divina», do per mitjà del qual una de les monges, en sentir-se afavorida per aquesta gràcia, s'alçava i proclamava la nova priora, que era acceptada després per les altres religioses ${ }^{8}$. Així, una de les darreres priores perpètues, Blanca Pujades, morí el febrer de 1500. Reunit el capítol sota la direcció del degà capitalici Jaume de Filella, la monja Agnès de Rocacrespa designà per inspiració Francina de Vilanova nemine discrepante. Altres vicissituds sobre aquesta forma d'elecció de les priores, com l'escrutini i el compromís, es poden veure al llibre mencionat a la nota núm. 4.

Finalment, s'ha de fer constar que «lo petit francès» surt, per exemple, a l'època del lloctinent Joan d'Anjou, a les llistes dels soldats de l'exèrcit $i$, altres vegades, demanant cases o pertinències de gent que s'havia passat al bàndol de Joan II, i que ha-

${ }^{5}$ Rocacrespa $=$ Caseria $\mathrm{i}$ antiga quadra del municipi de Cubelles (Garraf), GEC.

- Martinez Ferrando, J.E. Catálogo de la documentación de la Cancillería regia de Pedro de Portugal (1464-1466), 2 vol., Dirección General de Archivos y Bibliotecas, Madrid 1954. És a dir, que no va venir precisament acompanyant els soldats de Joan d'Anjou, sinó que ja voltava per Catalunya quan hi havia el seu antecessor, el Conestable.

7 Joan May va exercir aquests mateixos càrrecs en temps del Conestable. A les Cartes reials de l'època s'hi pot veure la seva signatura, segura, inalterable. Vegeu també el llibre mencionat a la nota anterior.

${ }^{8}$ Vegeu el llibre citat a la nota 4 , Les eleccions... 
vien abandonat els seus béns. El seu nom, no pas renom, era el de Llorenç de Bellfort'.

A continuació, ens referirem a la monja Marquesa de Santa Pau, que ja l'any 1458 les monges no la volien admetre perquè era massa gran i perquè la renda que rebia el monestir era massa justa ${ }^{10}$. En tot cas, no devia ser tan gran, ja que va morir cap al 1500. Sobre aquesta monja, Pelayo Negre y Pastell, a la seva monografia, «tirada aparte de los Anales del Instituto de Estudios gerundenses del Patronato "José Quadrado"》 que, generosament ens va facilitar la Srta. Costa", diu, no s'explica com en un document datat el 7 de maig 1506, de l'Arxiu Notarial de Barcelona, la monja Marquesa figura com a única filla «y heredera universal de Aldonza de Santa Paus.

Els documents referents a aquesta dama de Jonqueres potser ajudaran a aclarir alguna cosa. En primer lloc, tots dos estan datats a Torroella de Montgri, és a dir, quan el lloctinent Joan d'Anjou feia la guerra a l'Empordà, però, malgrat aquesta preocupació, va concedir a l'animosa monja:

a) Que els habitants i capitostos de Sant Celoni li facin arribar puntualment les pensions d'un censal que pertanyia a la seva mare, Aldonça de Santa Pau, difunta, que residia a Barcelona i tenia molts creditors que no volien aixecar les empares. Els regidors de Sant Celoni han de lliurar les quantitats degudes a $D^{a}$ Marquesa, que renuncia a una tercera part de les mateixes per reparar el castell d'Hostalric, en condicions precàries de defensa (doc. III).

b) Que tots els béns, censals i altres pertinències de la seva citada mare ja difunta passaven directament a ella, dei-

9 Aixi, el doc, núm. 2397 del 12 agost 1465, on s'ordena que acon fondos de la venta de dátiles, se paguen a Lorenzo de Bellfort, en concepto de gracia $y$ para ponerse en condiciones de ir a Cervera». Martinez FerRando, llibre citat a la nota 6.

${ }^{10}$ Costa, Les dames nobles... p. 292.

I" Negre I Pastell, Pelayo, El testamento de Doña Violante de Cruilles y de Santa Pau. Nolas genealógico-históricas del linaje Cruilles de Santa Pau. AIEG, XV, anys 1961-1962 (p. 72, núm. 25). 
xant de banda els drets del seu germà Guillem de Santa Pau, que per aquells temps continuava fidel a Joan II. Per això, Pelayo Negre no trobava el testament de la mare de $\mathrm{D}^{\mathrm{a}}$ Marquesa a favor seu i sí el testament d'aquesta a favor de la seva biografiada ${ }^{12}$ (doc. II).

Aquest darrer document està redactat pel secretari de Joan d'Anjou, que va rebre el càrrec de notari pùblic a Catalunya, Lorenzo de Varcio, natural de la ciutat d'Alessandria. Portava el segell pendent del Lloctinent i van actuar, com a testimonis: el rector de Badalona, els cavallers Joan de Lorena Harcourd, potser parent de Ferry de Vaudemont, gendre del rei René, i Joan de Torrelles, baró d'Ischia, segurament del seguici del Lloctinent. També hi figuren els cavallers catalans Bernat Turell i Bartomeu Lena.

La data resulta molt aparatosa, perquè el rei René es fa titular: «Sereníssim Senyor Rei de Jerusalem, Sicilia ultra farum, any XXXIII i dels altres regnes d'Aragó, principat de Catalunya, regne de València, comte de Barcelona, etc., segon»».

El darrer document referent a la priora de Jonqueres, Agnès Romeu, que actuà de 1468 a 1491, exposa la seva protesta davant de Joan d'Anjou, perquè l'abat de Montserrat, «estimat conseller Antoni Pere», retenia les butlles pontifícies, redactades pel papa Pau II a Roma, on, amb tots els requisits, es parlava de la monja Agnès Romeu com a priora, en data de gener 1468 . L'abat de Montserrat ho havia comentat amb altres persones, eclesiàstiques o no, però el mes d'agost la interessada encara no havia rebut les butlles i altra documentació. Realment, Joan d'Anjou estava desconcertat per l'acció de l'abat montserratí,

12 Fuvia I Escorsa, Armand, dins La Gran Enciclopèdia Catalana (vol. 13) publica la Genealogia de la familia Santa Pau. Da Marquesa, la monja, era filla, segons diu, de Galceran I Ademar i potser portava aquest nom per una tia seva, Marquesa, que es va casar amb Elf de Proixida. Ara bé, en el document citat per nosaltres, la seva mare s'anomena Aldonça i, a la Genealogia publicada per la Gran Enciclopèdia, el pare de la monja Marquesa es va casar dues vegades: la primera, amb Violant Rois de Liori i la segona, amb D² Marquesa de Cardona. La monja era filla de la primera muller, indica. 
que en la Guerra dels deu anys, com ens deia el nostre benvolgut i enyorat professor Vicens Vives, en va fer de totes. Potser l'abat de Montserrat aspirava a la nominació de la seva germana, Germana Ferrer ${ }^{13}$. (doc. IV)

13 La majoria d'aquests personatges figuren a la Comunicació que es va publicar als Cuadernos de Historia Jerónimo Zurita, 14-15, de la Institución Fernando el Católico (CSIC), de la Excma. Diputación Provincial de Zaragoza, 1963, pp. 31-54, que porta aquest titol: «Aspectos de la dominación angevina en Cataluña (1466-1472). La participación italiana y francesa en la revolución contra Juan II de Aragón». Aquesta Comunicació l'haviem presentat al V Congrés d'Història de la Corona d'Aragó, celebrat a Saragossa l'any 1952. 


\section{APÈNDIX DOCUMENTAL}

\section{Document I}

1467, desembre 24, Barcelona

ACA. Intrusos. $34, f .45$

L'infant Joan d'Anjou, primogènit i lloctinent del rei René a Catalunya, al jurista Joan May, Li encomana la solució del conflicte entre les germanes Agneta, monja de Santa Maria de Jonqueres i Violant, donzella, d'una part i de l'altra, l'anomenat «lo petit francès», soldat de Joan d'Anjou. Les germanes eren filles del cavaller Pere Antoni de Rocacrespa.

PRO RELIGIOSA AGNETA, moniali Monasterii beate Marie de Junqueriis.- Infans Joannes, etc. Dilecto et fideli consiliario regio et nostro Joanni May, legum doctori, cancellariam regenti, salutem et dileccionem. Causam vertentem inter fideles regias et nostras religiosam Agnetem, monialem monasterii beate Marie de Junqueriis, Barchinone, ordinis Sancti Iacobi et Yolantem, domicella sorores, filias Petri Antonii de Rochacrespa, militis, regie maiestati et nobis rebellis, ex una, et fidelem armigerum nostrum, vulgo nominatum «lo petit françés», ex altera partibus, quam dudum propter dictarum sororum paupertatem, de qua legittime nobis constat, ad regiam sive nostram evocavimus audienciam eamque vive vocis oraculo vobis commisimus, queque propter nostrum felicem recessum quem impresenciarum ab hac "civitate» facimus terminari non potuit; vobis harum serie ad decidendum ducimus committendam. Mandantes vobis, quatenus vocatis ad vos partibus predictis et aliis quos vocandos noveritis, ipsisque in earum iuribus ad plenum auditis de dicta causa eiusque meritis cognoscatis eamque decidatis et fine debito terminetis, prout ius et racio postulabunt, procedendo in eisdem breviter, simpliciter, summarie et de plano, sola factu veritatis attenta, maliciis et diffugiis omnibus ultroiectis. Nos enim, vobis in et super his deppendentibus, emergentibus et connexis vices nostras committimus plenarie per presentes. Datum Barchinone, XXIIII mensis decembris anno a nativitate Domini millesimo CCCC L X V II. May, regens.- Bartholomeus Sanxo ex provisione facta per regentem cancellariam.- Probata.

\section{Document II}

1468, gener 25. Torroella de Montgri $A C A$. Intrusos 50, f. 124 o $C X X I$ 
Donació total a favor de la monja Marquesa de Santa Pau de l'herència materna i de la qual es descarta un germà, Guillem, fidel a Joan II.

PRO MARQUESIA DE SENTAPAU, moniali.- Pateat universis et singulis, presentem seriem inspecturis. Quod nos, Infans Joannes, Serenissimi Domini Regis primogenitus, etc-- Ad nonnullorum regiorum domesticorum et nostrorum pro infrascriptis nobis humiliter supplicantium intercessus. Tenore presentis regie et nostre carte cunctis et perpetuis temporibus valiture per dictum dominum Regem et nos, omnesque heredes et successores quoscumque suos et nostros, de nostra certa sciencia et consulto, illis scilicet, melioribus via, modo et forma, quibus de iure vel de facto possumus donatione quidem pura, perfecta, simplici et irrevocabili inter vivos damus, donamus, concedimus et graciose elargimur vobis nobili, relígiose et dilecte Regie et nostre, Marquesie de Sentapau, moniali monasterii beate Marie de Jonqueriis, civitatis Barchinone, ordinis Sancti Iacobi de Spata et vestris heredibus et successoribus et quibus volueritis perpetuo omnia et singula bona mobilia et immobilia, redditus, censualia mortua et violaria, eorumque precia et pensiones ac proratas debitas et debendas, scilicet, que fuerunt nobilis Aldoncie de Sentapau, quondam, matris vestri dicte Marquesie, que diu est in dicta civitate Barchinona decessit, ubicumque sint, fuerint aut reperiantur intra hunc Cathalonie principatum: et post eius decessum ad nobilem Guillermum de Sentapau, rebellem, dicte Aldoncie filium, ante sui rebellionem et patrie desercionem pertinebant seu pertinere debebant iure sucessionis eius matris. Et ob ipsius rebellionem notoriam ad prefatum dominum Regem et ad nos pertinent et spectant seu alias ex confiscacione hodie apud curiam nostram de predictis facta pertinent et pertinere debent. Hanc autem donacionem et ex causa donacionis, concessionem et graciam, facimus nos, dictus primogenitus et locumtenens generalis vobis prefate Marquesie et vestris et quibus volueritis perpetuo de predictis omnibus et singulis, pure, libere et absolute, absque aliqua condicione, retencione, sicut melius, plenius ac utilius dici potest et intelligi ad sanum et bonum etiam intellectum vestri et vestrorum predictorum in his successorum. Et extrahimus predicta que vobis et vestris ut supra damus de iure, dominio, proprietate et posse dicti domini Regis et nostri, nostrorumque heredum et successorum. Eademque in vestrum vestrorumque ius, dominium, proprietatem et posse mittimus et transferimus irrevocabiliter pleno iure ad habendum, apprehendendum, tenendum, consequendum, possidendum ac penes vos et vestros licite retinendum, vendendum, alienandum, impignorandum et alias ad vestras vestrorumque omnimodas voluntates, inducentes seu inducere promittentes tradereque vobis et vestris aut cui volueritis possessionem corporalem seu quasi realem et actualem premissorum que vobis ut supra dona- 
mus. Quam possessionem, si malueritis vos vel vestri possitis libere apprehendere et apprehensam licite retinere tanquam rem vobis et eis donatam et concessam, sine contradiccione et impedimento dicti domini Regis et nostri aut alterius cuiuscumque persone. Preterea ex causa huiusmodi donacionis, concessionis et gracie, damus, cedimus et mandamus vobis et vestris predictis, omnia iura, omnesque acciones reales et personales, mixtas, utiles et directas, ordinarias et extraordinarias et alias quascunque dicto domino regi et nobis competencia et competentes, competereque debentia et debentes in predictis omnibus que vobis et vestris ut supra donamus et concedimus. Quibus iuribus et accionibus predictis possitis vos et vestri possint uti, agere et experiri in iudicio et extra iudicium quemadmodum dictus dominus rex et nos facere poteramus ante presentem donacionem iuriumque et accionum cessionem, possemusque nunc et postea quandocunque. Nos enim, ponentes vos et vestros in locum, ius, vicem et privilegium dicti domini Regis et nostrum facimus et constituimus vos et vestros in his dominos et procuratores ut in rem vestram propriam ad habendum, tenendum, exigendum et percipiendum omnia et singula predicta et de eis vestras vestrorumque voluntates faciendum iuribus tamen regiis et nostris fideliumque nostrorum semper salvis. Gerentivices, igitur, nostre generalis gubernationis in hoc Cathalonie principatu, Baiulo quoque generali et thesaurario regio et nostro aliisque officialibus et personis dicti domini regis et nostris ad quos spectet et dictorum officialium locatenentibus presentibus et futuris, tradimus firmiter in mandatis quatenus donacionem huiusmodi et omnia et singula predicta teneant firmiter et observent, tenerique et observari faciant iuxta suai seriem pleniorem, vosque et vestros predictos in possessionem omnium predictorum ponant et inducant positumque et inductum manuteneant, et deffendant viriliter contra cunctos. Necnon ii eorum ad quos spectet vobis et vestris predictis de predictis censibus, censualibus, violariis et aliis predictis respondeant et satisfaciant, integre et complete, prour et quemadmodum dicte nobili Aldoncie, quondam, si vixisset aut dicto Guillermo de Sentapau, eius filio rebelli, si fidelis esset, responderent et satisfacerent ac parerent. Et contrarium non faciant aut fieri permittant racione aliqua sive causa. In cuius rei testimonium presentes expediri iussimus, sigillo locumtenentis impedenti munitas. Datum et actum in villa Turricelle de Montegrino, die $\mathrm{XXV}^{\circ}$ ianuarii, anno a nativitate Domini Millesimo $\mathrm{CCC}^{\circ}$ sexagesimo octavo, regnorumque vero dicti Serenissimi domini Regis Hierusalem, Sicilie citra farum etc. anno $\mathrm{XXXIII}{ }^{\circ}$; aliorum vero regnorum suorum anno secundo.

Signum... Infantis Joannis, qui predictam donacionem et graciam omniaque et singula in ea contenta laudamus, concedimus et firmamus. Johannes 
Testes sunt: venerabilis Ja(cobus) Torres, rector Bitulone.

Joannes de Lothoringia Aricurie

Joannes de Torillis, Iscle comites

$\left.\begin{array}{l}\text { Bernardus Turell et } \\ \text { Bartholomeus Lena }\end{array}\right\}$ milites

Sig. ... num mei Laurencii de Varcio, prefatorum sere-

nissimi domini Regis ac illustrissimi eius primogeniti et locumteis generalis secretarii ac per omnem dicionem ipsius domini Regis notarii publici, qui de ipsius domini primogeniti mandato premissis interfui eaque scribi feci et clausi.

Dominus primogenitus et locumtenens generalis mandavit mihi Laurencio de Varcio, in cuius posse firmavit. Vidit Jo(hannes) $\mathrm{Pi}$, locumtenens thesaurarii et Franciscius Maleti, pro fisci advocato. Probata.

\section{Document III}

1468, gener, 25. Torroella de Montgri

ACA. Intrusos, 33 f. 152

L'infant Joan d'Anjou, a les autoritats i habitants de Sant Celoni, perquè no posin dificultats a la monja Marquesa de Santa Pau, que té dret a rebre les pensions d'un censal de la seva mare, ja difunta.

PRO MARQUESIA DE SENTAPAU MONIALI.- Infans Joannes, etc.- Fidelibus regiis et nostris, iuratis et probis hominibus atque singularibus ville Sancti Celedonii, salutem et graciam. Querelosa expositione nobilis et religiose ac dilecte nostre Marquesie de Sentapau monialis, monasterii beate Marie de Jonqueriis, civitatis Barchinone noviter accepimus, quod, cum ipsa quoddam censuale mortuum in et super dicta universitate habeat et possideat, sitque in possessione recipiendi illud; vos, tamen, ex causa nonnullarum empararum in pensionibus dicti censualis factarum ad instanciam quorumdam creditorum nobilis Aldoncie de Sentapau, quondam, dicte Marquesie matris, et alias, recusastis et recusatis dicti censualis pensiones dicte Marquesie solvere in eius quam maximum preiudicium dampnumque atque detrimentum non parum cum ipsa non sit heres nec bona aliqua dicte sue matris teneat. Ob quod pro ipsius Marquesie parte nobis humiliter supplicatum extitit ut dictas emparas revocare seu cancellare et alias super premissis de congruo iusticie remedio sibi providere dignaremur, 
cum ipsa parata sit ius et de iure in posse nostro predictis et aliis quibusvis emparantibus firmare. Nos, itaque, causa huiusmodi ipsius monialis religionis pretextu ad regium hoc consistorium prius evocata, et indeipsa iuris firma admissa atque dicta supplicatione suscepta benigna vobis propterea et vestrum unicuique dicimus et districte precipiendo mandamus, de certa nostra sciencia et expresse sub incursu regie indignacionis et ire subque pena quingentorum florenorum auri Aragonum ut pensionem et pensiones dicti censualis debitam seu debitas predicte Marquesie seu eius procuratori tradatis et solvatis, quibusvis emparis seu aliis impedimentis in dicta pensione seu pensionibus censualis predicti factis seu faciendis non obstantibus ullo modo. Attento quod pro parte dicte Marquesie in hac regia seu nostra curia firmatum est ius et de iure pro decem solidis, pro augmento dictis et aliis quibusvis emparantibus iuxta morem regie cancellarie. Retenta tamen, tercia parte dicte pensionis seu pensionum pro conservacione castri Hostalrici, prout in provisione inde facta continetur. Ubi vero vos fortasse post presentium literarum nostrarum, vobis faciendam presentacionem requisiti dictam pensionem seu pensiones censualis predicti dicte Marquesie seu eius procuratori solvere recusaveritis seu distuleritis quoquomodo. Mandamus de dicta certa nostra sciencia et expresse sub dicta pena baiulo dicte ville ut secundum formam obligationum et contractuum censualis predicti, vos et vestrum unumquenque ad solvendum dicte Marquesie dictas pensionem seu pensiones quascunque debitas occasione censualis predicti una cum missionibus et expensis legittime factis et faciendis, mediante iusticia compellat, procedendo in et super premissis breviter, simpliciter, summarie et de plano, sola facti veritate attenta, maliciis, difugiis et dilacionibus cessantibus quibuscumque iurisfirma in posse nostro predicta prestita ut prefertur attenta. Et contrarium non faciatis neque faciat, si regiam graciam et nostram caram habetis et habet, iramque et indignacionem ac penam predictam cupitis et cupit non incurrere.

Datum in villa Turricelle de Montegrino die $\mathrm{XXV}^{\circ}$ ianuarii anno a nativitate Domini $\mathrm{M}^{\circ}$ CCCC LX V III.- May, regens.

Antonius França, ex provisione facta per regentem cancellariam. Probata. 
Protesta de Joan d'Anjou a l'abat de Montserrat, Antoni Pere Ferrer, en nom de la prioressa de Jonqueres.

PRO PRIORISSA DE JONQUERIIS.- Infans Joannes, etc. Venerabili et dilecto consiliario et cancellario nostro fratri Antonio Petri, abbati Monasterii Beate Marie de Monteserrato, ordinis Sancti Benedicti, Vicensis diocesis et aliis eciam quibusvis ecclesiasticis personis, et insuper gerentivices nostri officii generalis gubernatoris in Catalonie principatu, vicario et seu vicariam Barchinone regenti, baiulo, subvicario et subbaiulo dicte civitatis Barchinone, ceterisque universis et singulis officialibus dicti domini regis et nostris constitutis et constituendis ac notariis et tabellionibus quibuscumque, quibus presentes pervenerint et subscripta pertineant, presentibus et futuris, dictorumque officialium locatenentibus, salutem et dileccionem. Ne venerabilis et honesta religiosa dilecta dicti domini Regis et nostri Agnes Romeua, monialis Monasterii Beate Marie de Jonqueriis Barchinonensis, ordinis Sancti Jacobi de Spata, Uclensis, careat sicuti non decet, fructu literarum apostolicarum per Sanctissimum dominum nostrumdominum Paulum, divina providencia papam secundum ei concessarum datarum in Roma apud Sanctum Petrum, anno incarnacionis Dominice $\mathrm{M}^{\circ} \mathrm{CCCC} \mathrm{L} \mathrm{X} \mathrm{VIII}{ }^{\circ}$ idus ianuarii, pontificatus sui anno quinto, in et cum quibus per vos dictum abbatem mandatur ipsi provideri de prioratu dicti monasterii de Jonqueriis, prout hec et alia in dictas apostolicis literis in cordulis canapis vera bulla plumbea more Romane curie inpendenti bullatis, ad quas nos refferimus, lacius est videre, humilibus precibus pro ipsius parte nobis factis benigne annuentes predictis et aliis quibusvis apostolicis literis ac processibus per vos emanandis ac sentenciis et censuris inde fulminandis vobis, eidem abbati dicteque Agneti Romeua utendi eaque omnia et singula, tam coiunctim quam divisim, presentandi et execucionis effectui deducendi ac deduci requirendi plenam et absolutam vobis et ei concedimus licenciam et facultatem. Ideo vos, dictum abbatem et alias ecclesiasticas personas supradictas requirimus, monemus et hortamur quatenus literas apostolicas supradictas et processus, commissiones, sentencias et alia quevis rescripta et acta exequamini iuxta vobis in eis traditam formam, edictis, prohibicionibus et mandatis in contrarium per nos aut nostro nomine quovismodo factis et publicatis obsistentibus nullo modo. Vobisque dicto gerentivices gubernatoris, vicario et seu vicariam regenti, baiulo, subvicario et subbaiulo dicte civitatis Barchinone et aliis officialibus dicti domini regis et nostris, dicimus et mandamus sub regie ac nostre ire et indignacionis incursu, penaque florenorum auri de Ara- 
gonia trium milium regio erario aplicandorum quod in exequendis aut effectui debito deducendis predictis omnibus et singulis obstaculum seu impedimentum aliquod nullatenus prestis aut prestari faciatis vel permittatis sed auxilium brachii regii atque nostri libere impendatis si, quando et quociens inde fueritis requisiti. Necminus vobis dictis notariis iniungimus sub dicta peccunia quod de et superpredictis instrumenta et acta publica et auctentica inde necessaria et opportuna recipiatis et conficiatis, quibusque intersit tradatis quando et quotiens inde fueritis requisiti seu rogati, satisfacto vobis condecenter in vestris salario et labore. Datum Barchinone, die quarto mensis augusti anno a nativitate Domini $\mathrm{M}^{\circ}$ CCCCLXVIIII .- Jehan.

\section{Dominus primogenitus et generalis locumtenens mandavit mihi Ludovico Duranti.}

\section{Document $V$}

1473, desembre 4. Barcelona

ACA. R. 3387, f. 18

El rei Joan II, a les autoritats del regne d'Aragó, principat de Catalunya i regne de València, demanant que no posin cap impediment per a la recuperació dels seus béns, ja que des de Barcelona, ciutat llavors enemiga, pregaven al Cel per la seva salut i victòria.

MONASTERII DE JUNQUERIIS.- Joannes, etc. Reverendo, spectabili, nobilibus consiliariis nostris dilectis locumtenenti nostro generali in regno Valencie gerentibusque vices nostri generalis gubernatoris in regno Aragonum et Cathalonie principatu item et iusticie dicti regni Aragonum, deputatisque ipsius regni, insuper çalmedinis, vicariis et baiulis, iuratis et consiliariis, paciariis et procuratoribus civitatum nostrarum Cesarauguste, Barchinone, Dertuse, Ilerde aliarumque universitatum, villarum et locorum, ceterisque demum aliis officialibus nostris in dictis regnis et principatu constitutis et constituendis, quocunque nomine, officio et iurisdiccionem distinctis et locatenentibus eorumdem et aliis ad quos spectet, salutem et dileccionem. Menti habemus quod superioribus annis, informate quod religiose et dilecte nostre priorissa, moniales et conventus monasterii de Junqueriis, ordinis Sancti Jacobi de Spata, quamquam in eadem civitate tunc nobis inobediente comorarentur, tamen nobis fidelissime et affectatissime erant, suasque preces et oraciones ad Dominum pro nostri vita et in- 
columitate, nostrique status prosperitate continue porrigebant, nostris cum litteris inde expeditis, quarum datam totumque tenorem hic haberi volumus pro expressis, dictas priorissam, moniales et conventum ad omnia bona, census, censualia, decimas et alios redditus, emolumenta et iura quecunque que ubique regnorum et terrarum nostrarum antea possidebant, restituimus vobisque ac ceteris aliis ad quos attinebat iniunximus, precepimus et mandavimus quod easdem priorissam, moniales et conventum eorumque yconomum et procuratorem in pristinam possessionem omnium predictorum reduceretis, restitueretis et conservaretis eisque faceretis integre satisfieri et responderi per quoscunque debitores et obligatos de omnibus et singulis supradictis et aliis in quibus eisdem priorisse, monialibus et conventui tenebantur, prout in dictis litteris ad quas nos refferimus, plenius continetur. Que tamen littere et provisiones non fuerunt expedite; postea vero reducta Barchinona ad obedienciam nostram, in capitulacione nostra cum maiestate inita inter alia cautum est quod omnia monasteria, ceteraque loca pia religiosa et ecclesiastica recuperent omnia sua censualia, census, redditus, emolumenta, obvenciones et alia bona et iura que ante possidebant, non obstantibus quibusvis assignacionibus et consignacionibus aliisque per nos factis, prout in nono capitulo ipsius capitulacionis continetur expresse; propter quod nunc iterato suplicarunt nobis humiliter dicta priorissa, moniales et conventus ut predicta effectui mandari nostris cum literis et provisionibus opportunis dignaremur; nos enim, dictam suplicationem tanquam iustissimam et equissimam admittentes, vobis et singulis vestrum dicimus, precipimus et mandamus, de certa nostra sciencia et consulto ad penam duorum mille florenorum auri nostro erario si contrafeceritis aplicandam, quatenus visis presentis dictas priorissam, moniales et conventum seu earum yconomum et procuratorem in pristinam possessionem omnium et singulorum predictorum reponatis et restituatis, deque omnibus supradictis eis responderi et satisfieri faciatis, compellendo ad hec per debita et opportuna remedia omnes et singulos debitores et obligatos et ii vestrum et alii omnes et singuli qui predictis priorisse, monialibus et conventui universaliter et particulariter in aliquo teneamini et obligati sitis ipsis vel earum yconomo et procuratori et nemini alii respondeatis et satisfaciatis, dubio, difficultate et consultacione cessantibus quibusvis litteris, rescriptis et provisionibus a nobis in contrarium emanatis et inter alia quadam provisione pro nostre curie necessitatibus emanata vobisque procuratoribus civitatis Dertuse, receptoribus et clavariis illius directa que data est in villa de Figueriis, die XXVIII febroarii anno a nativitate Domini $\mathrm{M}^{\circ} \mathrm{CCCC} \mathrm{L} \mathrm{XX} \mathrm{II}^{\circ}$, quibus omnibus tenore presencium derogamus expresse. Cauti de contrario actentando aliqua racione vel causa quanto gracia nostra vobis cara est iramque et indignacionem nostram ac penam predictam cui prompta exequcio non deerit cupitis non incurrere. Datum Barchinone quarto 
die mensis decembris, anno a nativitate Domini $\mathrm{M}^{\circ} \mathrm{CCCC} \mathrm{L}$ XX III.Rex Jo(hannes)

Dominus Rex mandavit mihi, Bartholomeo Serena, visa per B. de Verino, vicecancellarium, Guillermum de Peralta, thesaurarium generalem, et Paulum Rossell, scribam porcionis, procuratorem regii patrimonii et pro conservatore. Probata. 